\title{
Identification of waterflooded zones and the impact of waterflooding on reservoir properties of the Funing Formation in the Subei Basin, China*
}

\author{
Peng-hui ZHANG ${ }^{1}$, Jin-liang ZHANG ${ }^{\dagger+1}$, Wei-wei $\mathrm{REN}^{1}$, Jun XIE ${ }^{2}$, Ming $\mathrm{LI}^{3}$, \\ Jing-zhe $\mathrm{LI}^{4}$, Fang DING ${ }^{1}$, Jin-kai WANG ${ }^{2}$, Zi-rui DONG ${ }^{5}$ \\ ( ${ }^{1}$ College of Resources Science and Technology, Beijing Normal University, Beijing 100875, China) \\ $\left({ }^{2}\right.$ College of Geological Science and Engineering, Shandong University of Science and Technology, Qingdao 266510, China) \\ $\left({ }^{3}\right.$ Henan Oilfield Research Institute, Nanyang 473132, China) \\ ( ${ }^{4}$ College of Marine Geosciences, Ocean University of China, Qingdao 266100, China) \\ $\left({ }^{5}\right.$ Schlumberger China, Chengdu 610041, China) \\ †E-mail: jinliang@bnu.edu.cn \\ Received June 30, 2012; Revision accepted Oct. 29, 2012; Crosschecked Jan. 23, 2013
}

\begin{abstract}
This paper describes the identification of waterflooded zones and the impact of waterflooding on reservoir properties of sandstones of the Funing Formation at the Gao 6 Fault-block of the Gaoji Oilfield, in the Subei Basin, east China. This work presents a new approach based on a back-propagation neural network using well log data to train the network, and then generating a cross-plot plate to identify waterflooded zones. A neural network was designed and trained, and the results show that the new method is better than traditional methods. For a comparative study, two representative wells at the Gao 6 Fault-block were chosen for analysis: one from a waterflooded zone, and the other from a zone without waterflooding. Results from this analysis were used to develop a better understanding of the impact of waterflooding on reservoir properties. A range of changes are shown to have taken place in the waterflooded zone, including changes in microscopic pore structure, fluids, and minerals.
\end{abstract}

Key words: Waterflooding, Reservoir properties, Neural network, Gao 6 Fault-block, Gaoji Oilfield doi: $10.1631 /$ jzus.A1200165

Document code: A

CLC number: TE122; TE347

\section{Introduction}

The Funing Formation is the main exploration target in the Gaoji Oilfield of the Subei Basin in east China. Previous studies on the Formation have focused mainly on the reservoir's heterogeneity, the distribution of residual oil (Chen, 2003), and the burial history (Li et al., 2011) of the study area and

\footnotetext{
${ }^{\ddagger}$ Corresponding author

* Project supported by the National Natural Science Foundation of China (No. 41172109), the National Natural Science Foundation of Shandong Province (No. ZR2011DM009), and the Research Foundation for the Doctoral Program of Higher Education (No. 20110003110014), China

(C) Zhejiang University and Springer-Verlag Berlin Heidelberg 2013
}

adjacent areas. However, there have been few studies on the identification of waterflooded sands and the impact of waterflooding on reservoir properties. Development of freshwater injection in the Gaoji Oilfield dates back to 1995, and production throughout the field has continued until the present day. However, exploration still has a low efficiency. Therefore, there is an urgent need to carry out studies on logging the identification and evaluation of waterflooded zones, with the aim of improving the accuracy of the interpretation of residual oil saturation. Several attempts have been made to achieve this, but most were based on traditional methods that employ only single well $\log$ data to identify waterflooded zones. Application of such data has limitations and the success rate is less 
than $50 \%$. Because of the multiplicity of logging in the waterflooded zone, a comprehensive study was deemed necessary to provide an understanding of combination logging.

In recent years, artificial neural network methodology has been successfully applied to studies of reservoir rock properties (Baldwin et al., 1990), lithology (Rogers et al., 1992; Benaouda et al., 1999; Qi et al., 2004), porosity and permeability (Rogers et al., 1995; Ogiesoba, 2010), flow units (Aminian and Ameri, 2005), missing logs (Saggaf and Nebrija, 2003), seismic interpretation (Chawathé et al., 1997; Balch et al., 1999) and fractured reservoirs (Jenkins et al., 2009). This paper describes an approach based on a back-propagation neural network to identify waterflooded zones, and establishes an identification cross-plot plate using well log data. In addition, we examine the changes in reservoir parameters after waterflooding.

\section{Geological setting}

The Subei Basin is located in east China (Fig. 1a) and is tectonically divided into three major units: the Dongtai Depression, Yanfu Depression and Jianhu Uplift (Fig. 1b). The Gaoji Oilfield is a fault-block group that was formed during the Wubao movements in the northwest of the Dongtai Depression. A group of northeast-trending faults developed with the fault throws ranging between 40 and $140 \mathrm{~m}$ (Fig. 1c). The evolution of these faults controls the distribution of source rocks and reservoirs, which play an important role in the formation of hydrocarbon trapping in the

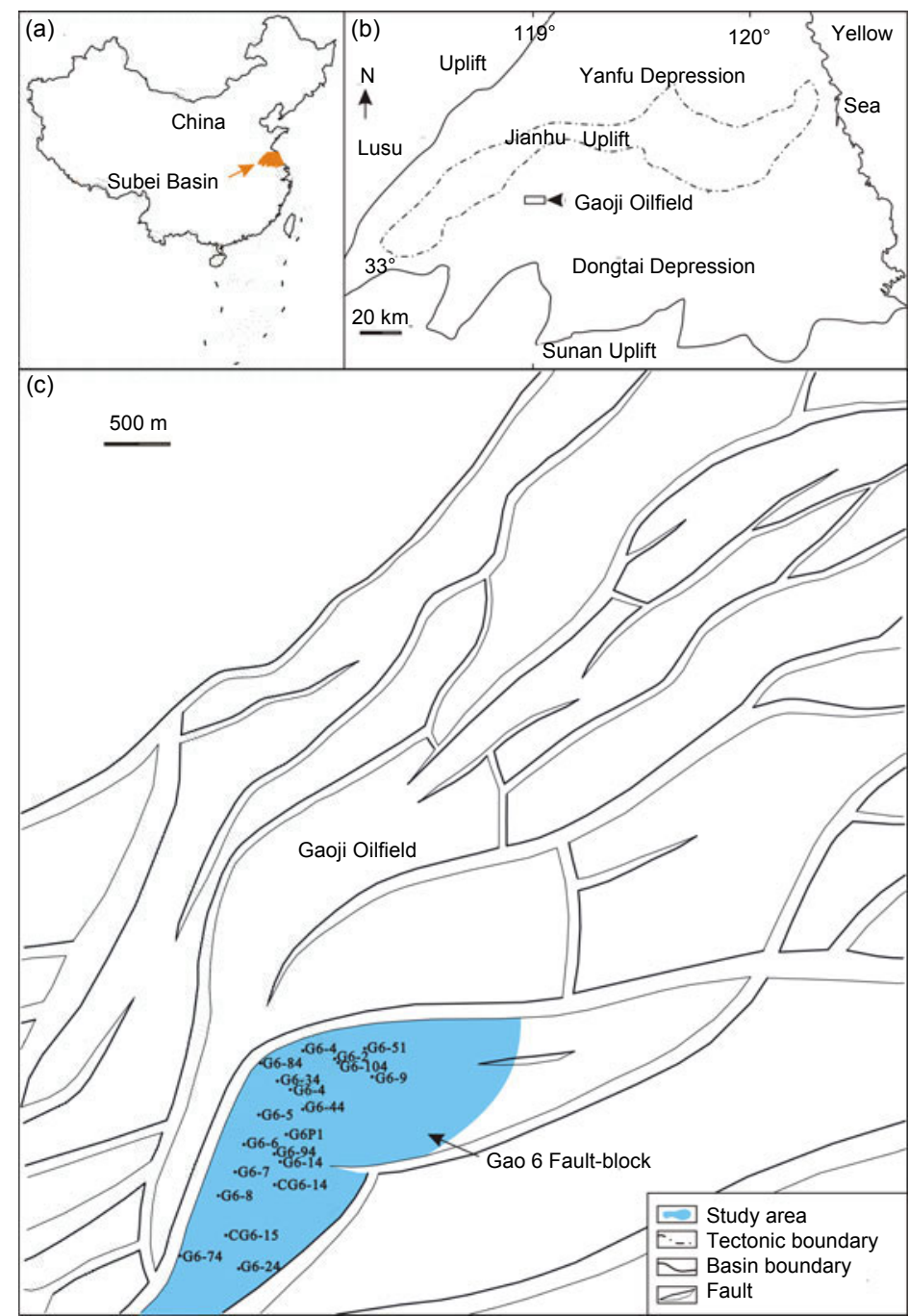

Fig. 1 Location map of the Gao 6 Fault-block of the Gaoji Oilfield in the Subei Basin 
study area. The Gao 6 Fault-block is one of the major producing blocks in the oilfield. It is composed of medium-porosity and low- to medium-permeability sandstone reservoirs of proven hydrocarbon reserves of $470 \times 10^{4} \mathrm{t}$.

\section{Materials and methods}

The back-propagation neural network is by far the most commonly used type of network. Input to the network consisted of a combination of five well logs: natural gamma ray (GR), acoustic log (DT), laterolog eight (RFOC), deep resistivity (RILD), and medium resistivity (RILM). The output variable was set to two dimensions in the neural network architecture, in which the code of the oil reservoir was set as $(0.25$, $0.25)$, the dry layer as $(0.25,0.75)$, the waterflooded zone as $(0.75,0.25)$ and the water layer as $(0.75$, 0.75 ). The network thus had an input layer consisting of five input neurons and two output layer neurons (Fig. 2a). Well logs of 160 sands were selected as training samples according to the well testing reports, including 40 oil sands, 40 dry sands, 40 waterflooded sands, and 40 water sands. Before network training, well logs must be normalized to make their values between 0 and 1 . The network was trained to adjust the network weights and thresholds according to the network prediction error to minimize the network error. This process continued until the mean squared error dropped to 0.09 , the best validation performance, after four-epoch network iterations (Fig. 2b). In this way, the training process achieved the identification accuracy goal for waterflooded zones.

After training, we superimposed the network output values and the well testing reports. A good correlation was obtained between the training samples and the target vectors, with a clear distinction between each category. Each category has different symbols representing the oil reservoir, dry layer, waterflooded zone, and water layer on the cross-plot plate (Fig. 2c). Thus, we have obtained a cross-plot plate to predict the presence of waterflooded sands in the Gao 6 Fault-block.

Ten sandstone samples were selected for modal analysis (300 points per thin section). An FEIQuanta Inspect SEM (G02342, the Netherlands) was used to observe the texture of clay minerals and their
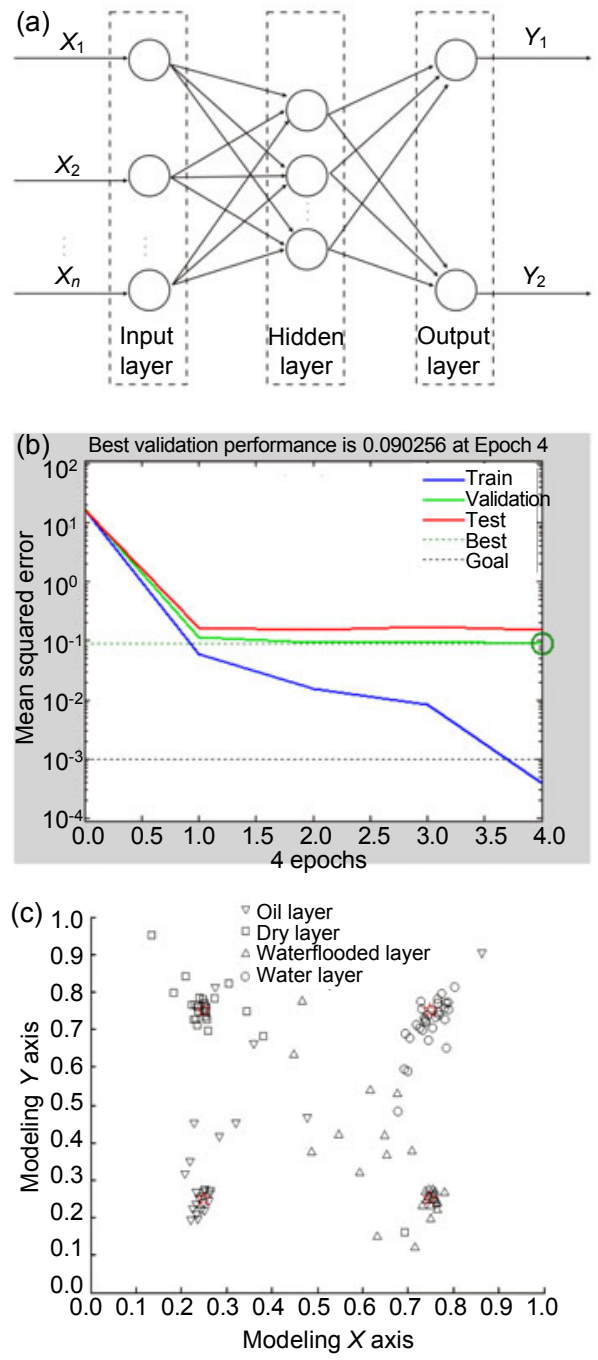

Fig. 2 Architecture of the back-propagation neural network (a); Network error according to the network predictions (b); Distinction of each fluid zone on the identification cross-plot plate (c)

porosity. The $\leq 2 \mu \mathrm{m}$ clay fraction was separated from the sandstones and analyzed by XRD, using a D/max-1200 (G02013, Japan) diffractometer.

\section{Results}

\subsection{Identification of waterflooded reservoirs based on the back-propagation neural network}

Using the above method, we selected well logs of another 20 adjustable sands, which we entered into the cross-plot plate to act as unknowns. From this we obtained the distribution of the recognition results, 
which consisted of 20 points representing the 20 adjustable sands on the cross-plot plate. By applying the Euclidean algorithm to calculate the distance from each point to the center of each fluid zone on the cross-plot plate, the nearest fluid zone was identified as the type applicable to each distribution point. As shown above, the back-propagation neural networks identified four different fluid zones.

Comparing the well testing reports with the neural network recognition results, we found that the network predicted 17 out of the 20 samples correctly (Table 1). This success rate confirms the ability of the neural network to act as an excellent tool to predict waterflooded reservoirs, and proves that it performs better than traditional methods in identifying waterflooded zones from well logs.

\subsection{Impact of waterflooding on reservoir properties}

To develop a complete description of waterflood conditions, it is necessary to predict not only the types of fluid zone but also what impact waterflooding has on reservoir properties. For this purpose, we selected wells G6-2 and G6-104, which are less than $40 \mathrm{~m}$ apart, to perform a comparative study. Whereas well G6-2 is located in an oil reservoir, well G6-104 is located in a waterflooded zone. There is a significant change in the amplitude of the spontaneous potential (SP) curve of well G6-104 (Fig. 3a). In addition, the baseline wanders a great deal, reflecting obvious changes in character within the interval, due to freshwater waterflooding.

\subsubsection{Changes in reservoirs after waterflooding}

Based on Folk (1980)'s scheme classification, sandstone core samples from the two wells (G6-2 and G6-104) are classified as lithic arkose. We can capture ripple bedding, low-angle cross-bedding and bioturbation from the core photos of the two wells, revealing the same type of sedimentary facies (Fig. 3b). However, the porosity of well G6-104 increases at a certain rate after waterflooding but the permeability shows no significant change. Also, carbonate cements slightly increase.

The total amount of clay minerals declines from $5.4 \%$ to $2.5 \%$ after waterflooding (Table 2 ). The contents of illite and chlorite, as well as the relative content of smectite, are reduced in well G6-104. Poor-crystal form kaolinite can be seen in local areas in the waterflooded zone, caused mainly by washing of the freshwater injection (Fig. 4a).

Table 1 Twenty discriminant results from test samples of ten wells

\begin{tabular}{ccccccccc}
\hline Well & GR & DT & RFOC & RILD & RILM & Depth (m) & $\begin{array}{c}\text { Well testing } \\
\text { reports }\end{array}$ & $\begin{array}{c}\text { Neural network } \\
\text { recognition results }\end{array}$ \\
\hline G6-48 & 65.38 & 253.44 & 27.76 & 23.19 & 25.94 & $2039.75-2040.88$ & Water layer & Water layer \\
G6-48 & 67.75 & 253.44 & 19.06 & 17.20 & 18.00 & $2041.00-2041.75$ & Water layer & Water layer \\
G6-48 & 66.88 & 245.36 & 20.73 & 16.88 & 17.68 & $2046.50-2047.88$ & Water layer & Water layer \\
G6-48 & 63.25 & 258.75 & 29.48 & 24.30 & 27.70 & $2062.13-2064.00$ & Water layer & Water layer \\
G6-72 & 77.87 & 234.52 & 21.79 & 17.81 & 19.84 & $1986.00-1987.00$ & Water layer & Water layer \\
G6-73 & 66.10 & 245.17 & 24.63 & 27.35 & 19.25 & $1980.63-1981.38$ & Oil reservoir & Oil reservoir \\
G6-73 & 70.00 & 226.07 & 23.49 & 25.78 & 18.58 & $1988.75-1989.25$ & Oil reservoir & Oil reservoir \\
G6-58 & 75.58 & 251.74 & 26.81 & 30.04 & 29.60 & $1927.15-1830.88$ & Oil reservoir & Oil reservoir \\
G6-53 & 81.00 & 236.09 & 16.01 & 16.50 & 15.94 & $1949.25-1949.75$ & Oil reservoir & Oil reservoir \\
G6-52 & 68.20 & 248.98 & 25.73 & 21.93 & 19.97 & $1985.50-1989.13$ & Oil reservoir & Oil reservoir \\
G6-51 & 75.49 & 226.21 & 12.47 & 12.35 & 9.87 & $1999.13-2002.50$ & Dry layer & Dry layer \\
G6-51 & 71.25 & 228.72 & 10.73 & 10.78 & 8.52 & $2013.75-2015.88$ & Dry layer & Dry layer \\
G6-63 & 66.76 & 243.44 & 13.41 & 20.79 & 20.41 & $1980.87-1981.50$ & Dry layer & Dry layer \\
G6-63 & 65.41 & 256.25 & 20.60 & 21.58 & 21.72 & $1991.75-1995.00$ & Dry layer & Waterflooded zone \\
G6-63 & 67.30 & 241.10 & 19.66 & 33.79 & 30.23 & $2000.00-2005.00$ & Dry layer & Oil reservoir \\
G6-35 & 70.00 & 249.42 & 10.30 & 13.02 & 15.97 & $2045.25-2046.75$ & Waterflooded zone & Water layer \\
G6-35 & 63.61 & 267.61 & 23.06 & 23.60 & 25.04 & $2047.13-2048.75$ & Waterflooded zone & Waterflooded zone \\
G6-71 & 74.84 & 249.24 & 18.64 & 15.75 & 18.13 & $1965.25-1965.75$ & Waterflooded zone & Waterflooded zone \\
G6-104 & 73.01 & 247.81 & 21.66 & 18.30 & 23.78 & $1905.10-1919.37$ & Waterflooded zone & Waterflooded zone \\
G6-104 & 69.91 & 243.61 & 18.82 & 14.29 & 16.20 & $1920.39-1938.98$ & Waterflooded zone & Waterflooded zone \\
\hline & & & & & & & & \\
\end{tabular}


(a)

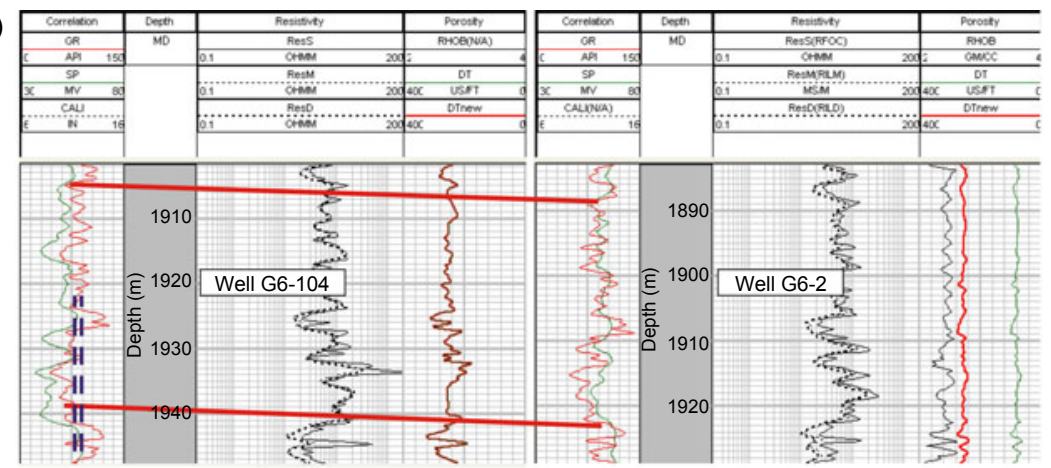

(b)

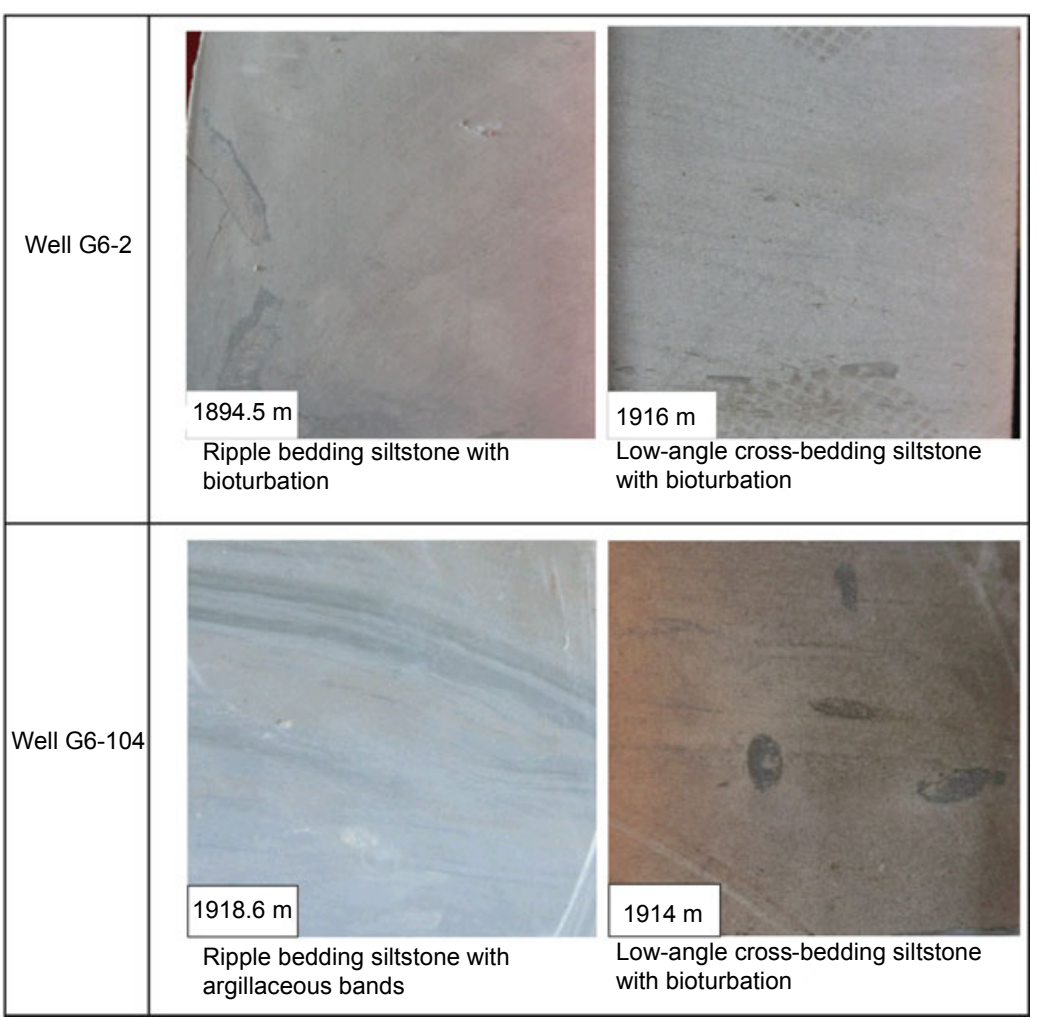

Fig. 3 Comparison of logging curves from well G6-104 and well G6-2 (a); Sedimentary facies of the core photos of the two wells (b)

Table 2 Reservoir properties before and after waterflooding

\begin{tabular}{cccccccccccc}
\hline Well & $\begin{array}{c}\text { Depth } \\
(\mathrm{m})\end{array}$ & $\begin{array}{c}\text { Helium } \\
\text { porosity }(\%)\end{array}$ & $\begin{array}{c}\text { Air perme- } \\
\text { ability }(\mathrm{mD})\end{array}$ & $\begin{array}{c}\text { Carbonate } \\
\text { cements }(\%)\end{array}$ & $\begin{array}{c}\text { Clay min- } \\
\text { erals }(\%)\end{array}$ & $\begin{array}{c}\mathrm{S} \\
(\%)\end{array}$ & $\begin{array}{c}\mathrm{I} / \mathrm{S} \\
(\%)\end{array}$ & $\begin{array}{c}\mathrm{I} \\
(\%)\end{array}$ & $\begin{array}{c}\mathrm{K} \\
(\%)\end{array}$ & $\begin{array}{c}\text { Ch } \\
(\%)\end{array}$ & $\begin{array}{c}\text { Oil saturation } \\
(\%)\end{array}$ \\
\hline G6-2 & $\begin{array}{c}1888.90- \\
1923.05\end{array}$ & 14.30 & 38.11 & 16.26 & 5.4 & 20 & 0.77 & 1.31 & - & 2.81 & 57.80 \\
G6-104 & $\begin{array}{c}1905.10- \\
1938.98\end{array}$ & 16.96 & 38.21 & 16.75 & 2.5 & 15 & 0.54 & 0.63 & 0.28 & 1.06 & 31.06 \\
\hline
\end{tabular}

S: smectite; I/S: illite/smectite mixed layer; I: illite; K: kaolinite; Ch: chlorite

4.2.2 Microscopic pore structure changes in the waterflooded zones

The microscopic pore structure of the reservoirs is an important geological condition that determines fluid flow and hydrocarbon migration. We examined thin sections and SEM photomicrographs from the G6-104 and G6-2 wells. In well G6-104, results indicate that (1) the contacts between the grains are 
loose, (2) there is relative development of secondary intergranular pores (Figs. $4 \mathrm{~b}$ and $4 \mathrm{c}$ ), and (3) pore distribution becomes non-uniform, and some throats become thick and even mesh (Fig. 4c). However, well G6-2 has dense lithology, and the relations of pore throat connectivity are not clear (Fig. 4d).

\subsubsection{Changes in fluid after waterflooding}

The average water salinity of the original formation of the Funing Formation of the Gao 6 Fault-block is about $7866-8159 \mathrm{mg} / \mathrm{L}$, while the formation water salinity of well G6-104 has declined significantly to $3148 \mathrm{mg} / \mathrm{L}$.

With continuous displacement of oil by freshwater injection, water saturation of the waterflooded zone of well G6-104 has increased, with a corresponding decrease in residual oil saturation (Soo and Radke, 1986a; 1986b; Bedrikovetsky et al., 2011). The oil saturation of the waterflooded area dropped to $31.1 \%$ from $57.8 \%$, reflecting the strong washing experienced by the reservoir.

The relative permeability curves derived from the two wells were compared (Figs. 5a and 5b). The water saturation curve from the waterflooded zone generally translates to the right. The intersection of the curves from G6-104 also has a larger shift to the right compared with that of G6-2, a sign that is strongly characteristic of a freshwater waterflooded zone.

\section{Discussion}

These results confirm the feasibility of using a back-propagation neural network to identify waterflooded zones. Due to the limitations of the experimental data, the separation of dry layers from waterflooded zones by applying the technique on the cross-plot plate was incomplete. With the further exploration and development of the study area, it should be possible to produce a more complete separation using training based on supplementary well testing reports.

Based on the results of this work, this paper focuses on the mechanism of reservoir changes after waterflooding. Few changes occurred in permeability, whereas porosity shifted to the right (Fig. $5 \mathrm{c}$ ). The correlation between porosity and permeability (Zhang et al., 2008) tended to be better after a waterflood, showing that the sorting features of pores become better and pore structure seems more uniform. With the washing of the injection water, the reservoir forms

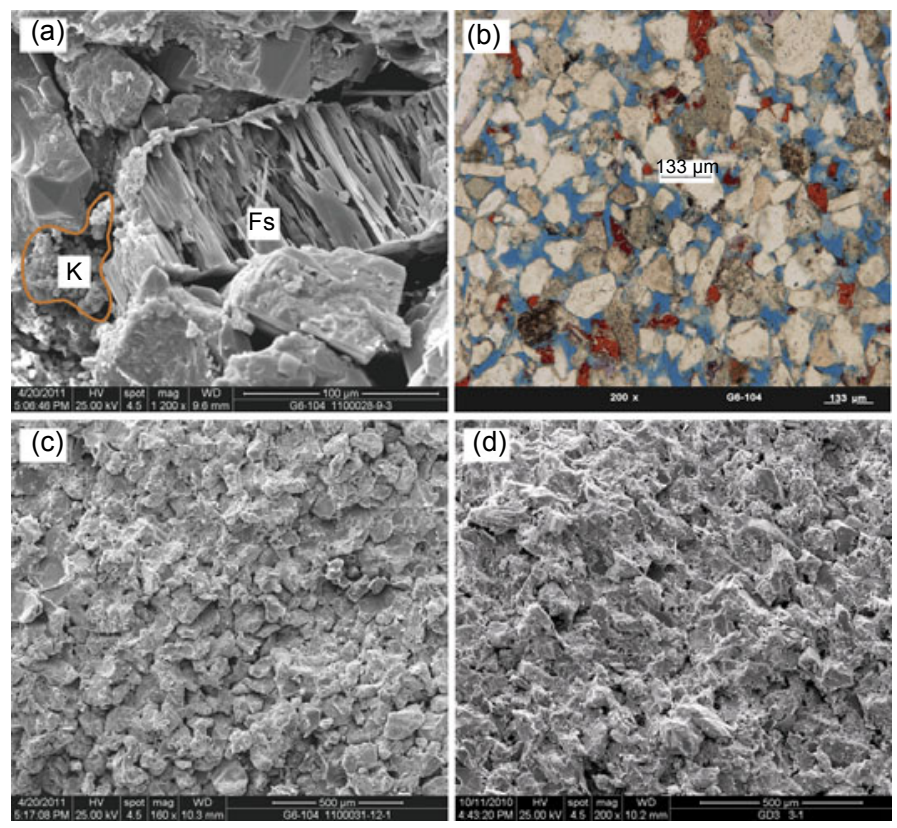

Fig. 4 Thin section and scanning election photomicrographs

(a) Kaolinite with poor crystal form in the waterflooded zone; (b) Development of secondary intergranular pores which increase porosity; (c) Non-uniform pore distribution after waterflooding in well G6-104; (d) Relatively dense lithology of well G6-2. K: kaolinite; Fs: feldspar 

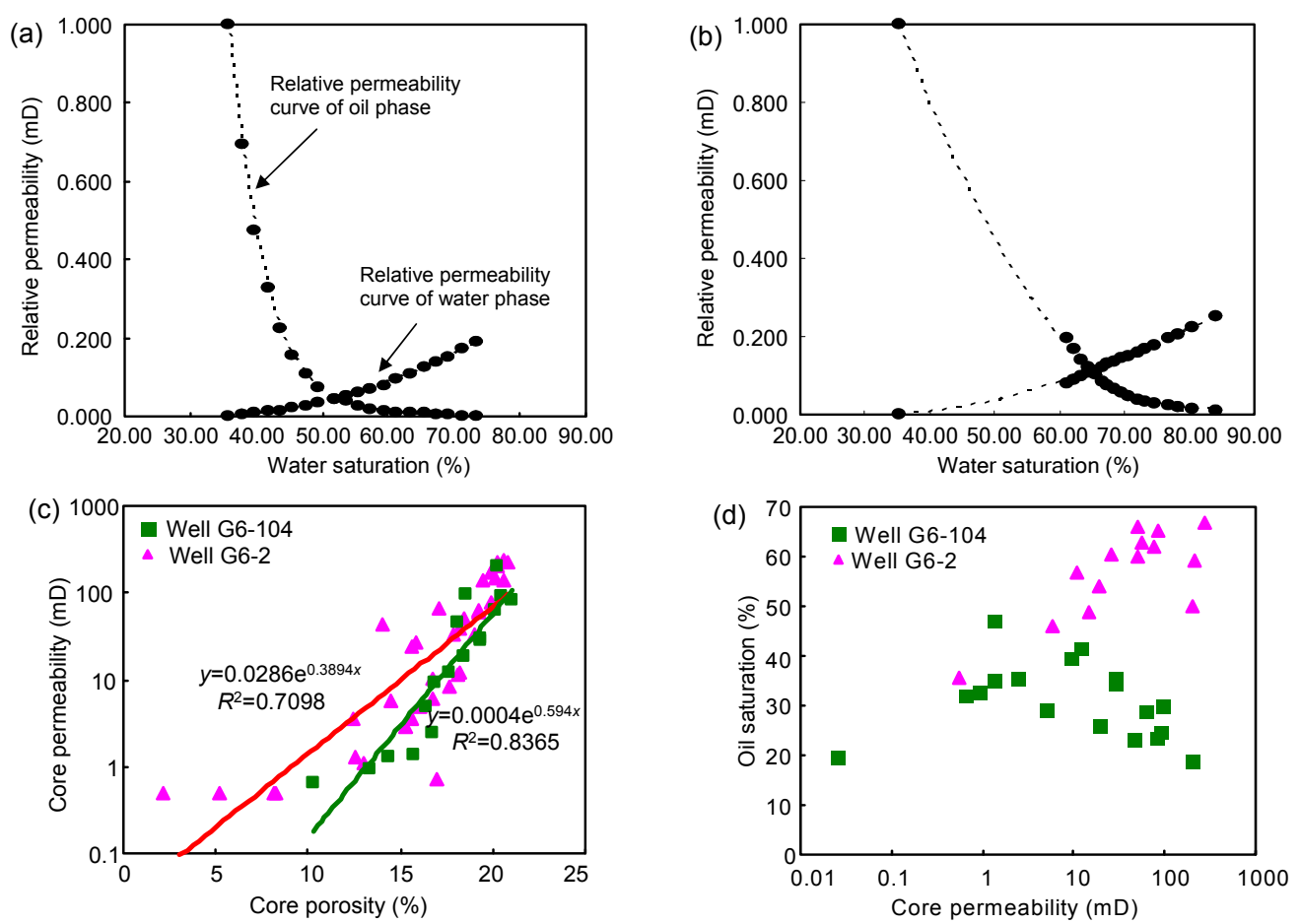

Fig. 5 (a) Relative permeability curves of the $E_{1} f_{2}^{3-2}$ sand body of well G6-2; (b) Relative permeability curves of the $E_{1} f_{2}^{3-2}$ sand body of well G6-104; (c) Plot of core porosity vs. core permeability revealing the correlation between porosity and permeability; (d) Oil saturation vs. core permeability showing a positive correlation in well G6-2 and a negative correlation in well G6-104

microfissures, and clay minerals of the cores are flushed out to propagate through the reservoir. Thus, the cores become larger, which increases their porosity.

Not only does the content of clay minerals change, but also their composition and structure. For example, illite has a filamentous role, and can cause a change in water or speed sensitivity. However, reservoir properties have not changed very rapidly due to the low content of clay minerals in the study area.

Oil saturation and permeability showed a strong positive correlation in well G6-2 (Fig. 5d). However, oil saturation in well G6-104 was significantly lower than that in well G6-2. Furthermore, there was a trend showing decreasing oil saturation as permeability increased, implying that well G6-104 has experienced tremendous amounts of waterflooding (Yang et al., 2000; Zhang and Xie, 2011).

\section{Conclusions}

1. In this study, a back-propagation neural network was used to accurately estimate waterflooded zones, by utilizing a combination of well logs composed of GR, DT, RFOC, RILD, and RILM. We used $89 \%$ of the data to train the network and $11 \%$ to act as unknowns. A neural network cross-plot plate for identification was set up, and the success rate was up to $85 \%$.

2. Secondary intergranular pores developed, increasing porosity after waterflooding, while the content of clay minerals declined as a result of washing migration. Apparent reductions occurred in the water salinity of the formation and the saturation of residual oil in the waterflooded zone.

3. A variety of physical and chemical changes have occurred in the reservoir after waterflooding, which have affected the composition and distribution of minerals.

\section{Acknowledgements}

The authors would like to thank the SINOPEC Jiangsu Petroleum Exploitation Bureau Geoscience Institute, China for supplying core samples, formation water analysis data and physical property data and for permission to publish this study. 


\section{References}

Aminian, K., Ameri, S., 2005. Application of artificial neural networks for reservoir characterization with limited data. Journal of Petroleum Science \& Engineering, 49(3-4): 212-222. [doi:10.1016/j.petrol.2005.05.007]

Balch, R.S., Stubbs, B.S., Weiss, W.W., Wo, S., 1999. Using Artificial Intelligence to Correlate Multiple Seismic Attributes to Reservoir Properties. SPE 56733 Presented at the SPE Annual Technical Conference, Houston, TX, p.3-6.

Baldwin, J.L., Bateman, R.M., Wheatley, C.L., 1990. Application of a neural network to the problem of mineral identification from well logs. The Log Analyst, 3:279293.

Bedrikovetsky, P.G., Nguyer, T.K., Hage, A., Ciccarelli, J.R., Wahab, M.A., Chang, G., Souza, A.L., Furtado, C.A., 2011. Taking advantage of injectivity decline for improved recovery during waterflood with horizontal wells. Journal of Petroleum Science and Engineering, 78(2): 288-303. [doi:10.1016/j.petrol.2011.05.020]

Benaouda, B., Wadge, G., Whitmarh, R.B., Rothwell, R., MacLeod, G.C., 1999. Inferring the lithology of borehole rocks by applying neural network classifiers to downhole logs - an example from the Ocean Drilling Program. Geophysical Journal International, 136(2):477-491. [doi:10.1046/j.1365-246X.1999.00746.x]

Chawathé, A., Quenes, A., Weiss, W.W., 1997. Interwell Property Mapping Using Crosswell Seismic Attributes. SPE 38747 Presented at the SPE Annual Technical Conference and Exhibition, San Antonio, TX, p.6-9.

Chen, Z., 2003. The reservoir heterogeneity and remaining oil distribution in Funing Formation in the Seventh Block of Gaoji Oilfield. Offshore Oil, 23(2):51-54 (in Chinese).

Folk, R.L., 1980. Petrology of Sedimentary Rocks. Hemphill Publishing, Austin, Texas, USA.

Jenkins, C., Ouenes, A., Zellou, A., Wingard, J., 2009. Quantifying and predicting naturally fractured reservoir behavior with continuous fracture models. AAPG Bulletin, 93(11):1597-1608. [doi:10.1306/07130909016]

Li, Y., Li, R., Chen, L., Song, N., Fang, J., 2011. Thermal history reconstruction and hydrocarbon accumulation period discrimination of Jinhu Depression in Subei Basin. Acta Sedimentologica Sinica, 29(2):395-401 (in Chinese). Ogiesoba, O.C., 2010. Porosity prediction from seismic attributes of the Ordovician Trenton-Black River groups, Rochester field, southern Ontario. AAPG Bulletin, 94(11): 1673-1693. [doi:10.1306/04061009020]

Qi, L.S., Carr, T.R., Goldstein, R.H., 2004. Geostatistical three-dimensional modeling of oolite shoals, St. Louis Limestone, southwest Kansas. AAPG Bulletin, 88(3): 303-324. [doi:10.1306/08090605167]

Rogers, S.J., Fang, J.H., Karr, C.L., Stanley, D.A., 1992. Determination of lithology from well logs using a neural network. AAPG Bulletin, 76:731-739.

Rogers, S.J., Chen, H.C., Kopaska-Merkel, D.C., Fang, J.H., 1995. Predicting permeability from porosity using artificial neural networks. AAPG Bulletin, 79:1786-1797.

Saggaf, M.M., Nebrija, E.L., 2003. Estimation of missing logs by regularized neural networks. AAPG Bulletin, 87(8): 1377-1389. [doi:10.1306/03110301030]

Soo, H., Radke, C.J., 1986a. A filtration modal for the flow of dilute, stable emulsions in porous media-I. theory. Chemical Engineering Science, 41(2):263-272. [doi:10. 1016/0009-2509(86)87007-5]

Soo, H., Radke, C.J., 1986b. A filtration modal for the flow of dilute, stable emulsions in porous media-II. parameter evaluation and estimation. Chemical Engineering Science, 41(2):273-281. [doi:10.1016/0009-2509(86)870087]

Yang, W., Liang, G., Zhao, X., Zhang, X., Zhao, P., 2000. Water flooding out characteristics of Anan sandstone oil reservoir at its medium later development stage. Petroleum Exploration and Development, 27(5):80-83.

Zhang, J., Xie, J., 2011. Development Geology. Petroleum Industry Press, Beijing (in Chinese).

Zhang, J., Qin, L., Zhang, Z., 2008. Depositional facies, diagenesis and their impact on the reservoir quality of Silurian sandstones from Tazhong area in central Tarim Basin, western China. Journal of Asian Earth Sciences, 33(1-2):42-60. [doi:10.1016/j.jseaes.2007.10.021] 